\title{
Lições da pedra (ensaio visual)
}

Ícaro Lira (Brasil) *

Com texto de Elena Lespes Muñoz (CAC Brétigny, França) **

https://doi.org/10.22409/poiesis.v21i35.40410

Nos últimos anos, Ícaro Lira vem analisando as implicações e os desdobramentos de atos políticos e históricos da História Brasileira através de um trabalho documental, arquivista, arqueológico e de ficção. Suas exposições apresentam estruturas similares a pequenos "museus", onde reúne diversos fragmentos esquecidos, produzindo um sistema de objetos que articula materiais artísticos e nãoartísticos, e um conjunto de ações, não necessariamente confinadas a um objeto artístico, mas dispersas em exposições, livros, oficinas, debates, caminhadas etc.

\footnotetext{
* Ícaro Lira (1986, Fortaleza, Ceará). Vive e trabalha em Fortaleza. Artista visual, editor e investigador, estudou na Escola de Artes Visuais do Parque Lage (Rio de Janeiro), Cinema e Vídeo na Casa Amarela-UFC (Ceará) e Montagem e Edição de Som no Instituto de Cinema Darcy Ribeiro (Rio de Janeiro). Participou do PIMASP, Programa Independente do Museu de Arte de São Paulo (SP). E-mail: icaronglira@gmail.com

** Elena Lespes Muñoz é historiadora de arte (Universidade de Paris I e Universidade de São Paulo), além de curadora de exposições (Le bruit des choses qui tombent, FRAC-PACA, 2017; Video SUR, Palais de Tokyo, 2018). Atualmente é gestora de comunicação e mediação da CAC Brétigny.
} 
Para Ícaro Lira, a história é matéria viva constantemente esmagada pelo peso das narrativas oficiais, escritas pelos mais poderosos. Em busca de contranarrativas, 0 artista coleta objetos, textos, relatos, imagens e fragmentos de lugares de conflito social. A partir destes, cria pequenos museus com materiais oriundos de sua pesquisa, que frequentemente abrange conjuntos de ações dispersas em exposições, livros, oficinas e excursões em campo. Em seu método de trabalho, a história é vista com uma lupa e a atenção é dada ao que os acontecimentos revelam de minúsculo e singular sobre o passado, e o que poderiam prever sobre o futuro.

\begin{abstract}
A Educação pela Pedra
Uma educação pela pedra: por lições;

Para aprender da pedra, frequentá-la;

Captar sua voz inenfática, impessoal (pela de dicção ela começa as aulas). A lição de moral, sua resistência fria Ao que flui e a fluir, a ser maleada;

A de poética, sua carnadura concreta;

A de economia, seu adensar-se compacta: Lições da pedra (de fora para dentro, Cartilha muda), para quem soletrá-la.

Outra educação pela pedra: no Sertão (de dentro para fora, e pré-didática). No Sertão a pedra não sabe lecionar, E se lecionasse, não ensinaria nada; Lá não se aprende a pedra: lá a pedra, Uma pedra de nascença, entranha a alma.
\end{abstract}

João Cabral de Melo Neto, 1965.

Citação recomendada:

LIRA, Ícaro. Lições da pedra (com texto de Elena Lespes Muñoz). Poiésis, Niterói, v. 21, n. 35, p. 87-108, jan./jun. 2020. [https://doi.org/10.22409/poiesis.v21i35.40410] 
LEÇONS DE LA PIERRE

ÍLARO LIRA

$21.11-01.02 .2020$ 


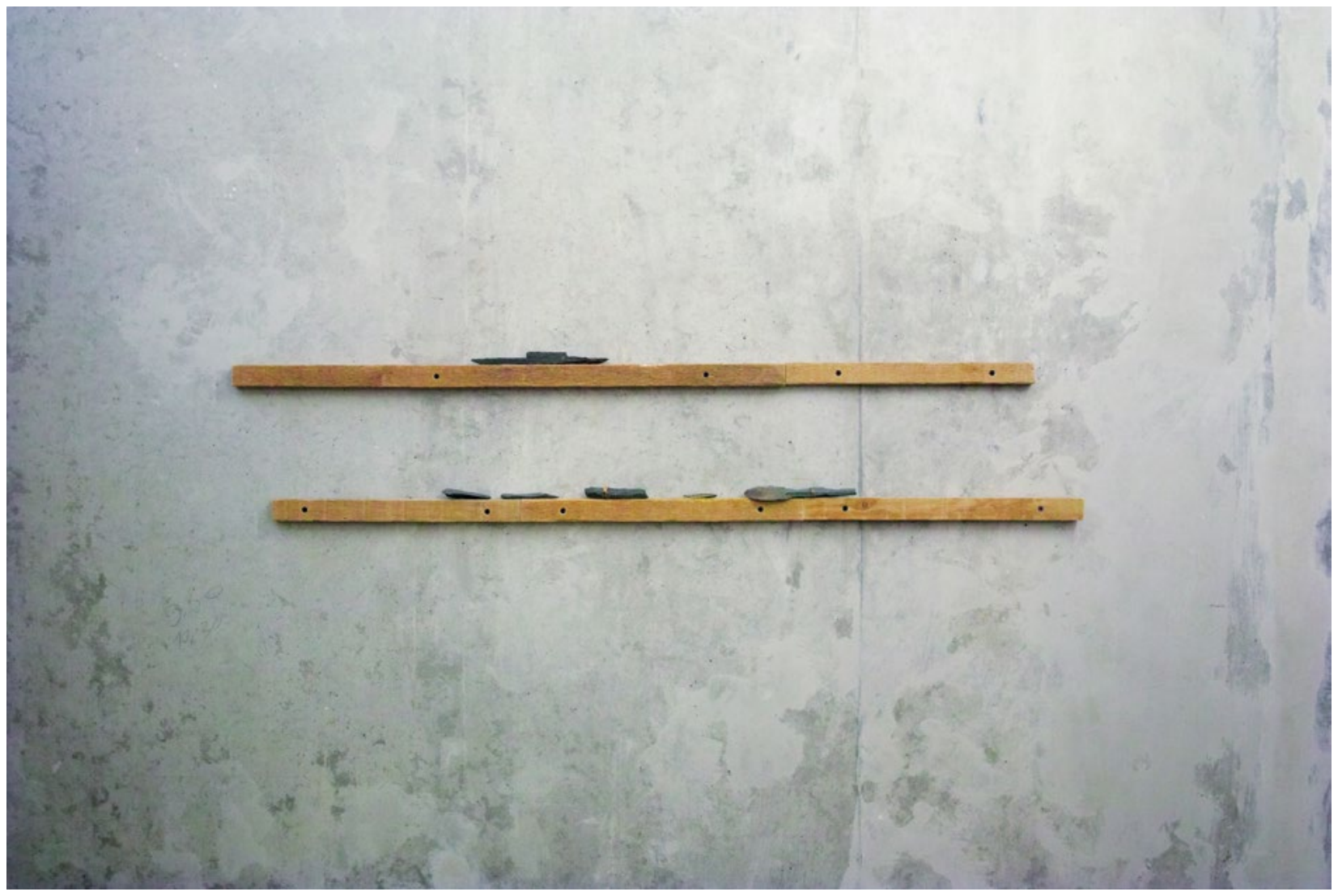

1.

Sem Título | 2019

Madeira, Ardósia, Cobre e Pregos.

$125 \times 25 \times 2 \mathrm{~cm}$ 


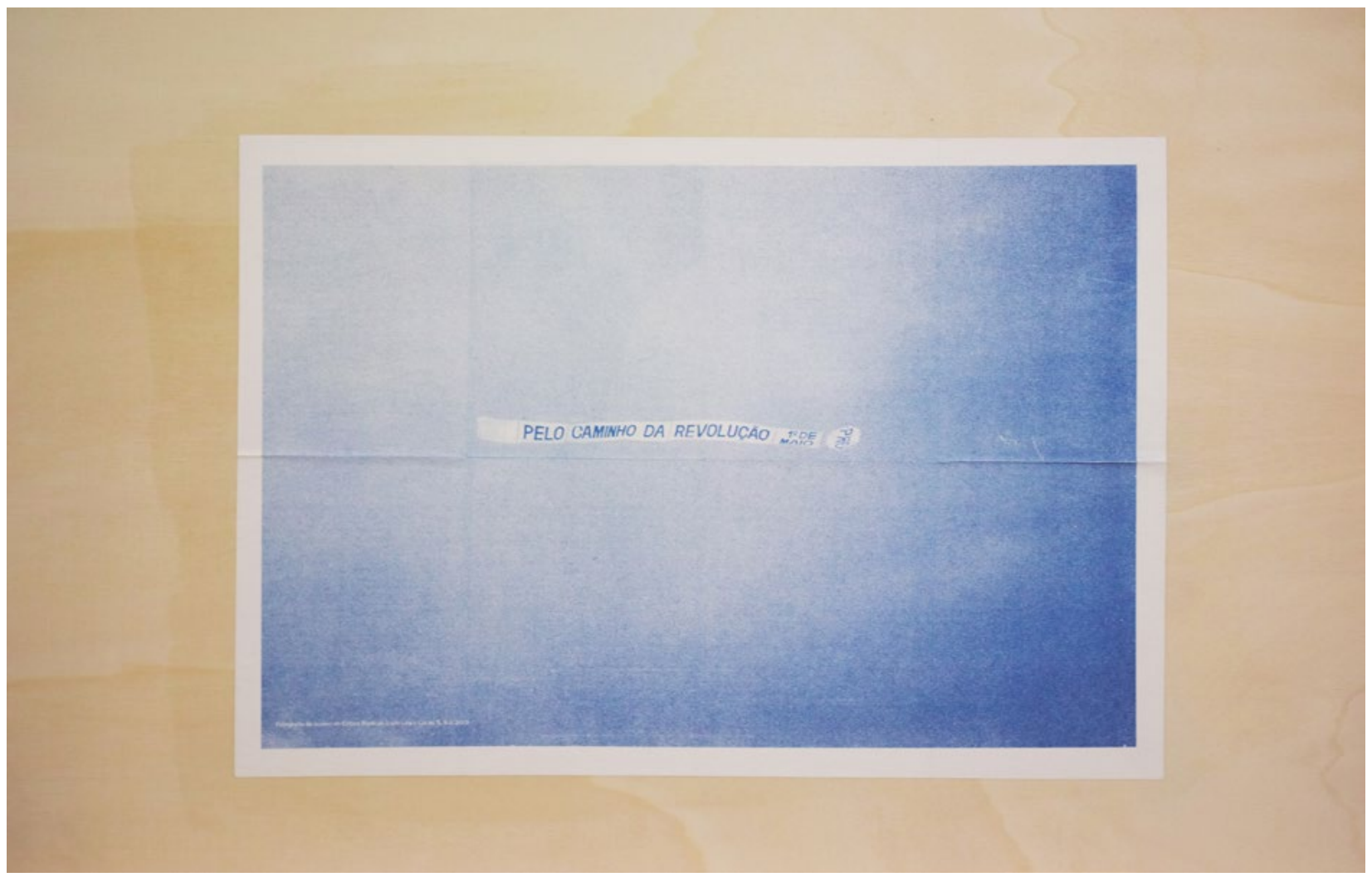

2.

Critíca Radical | 2019

com colaboração de Lucas S. Icó

Impressão em Risografia.

$42 \times 30 \mathrm{~cm}$ 


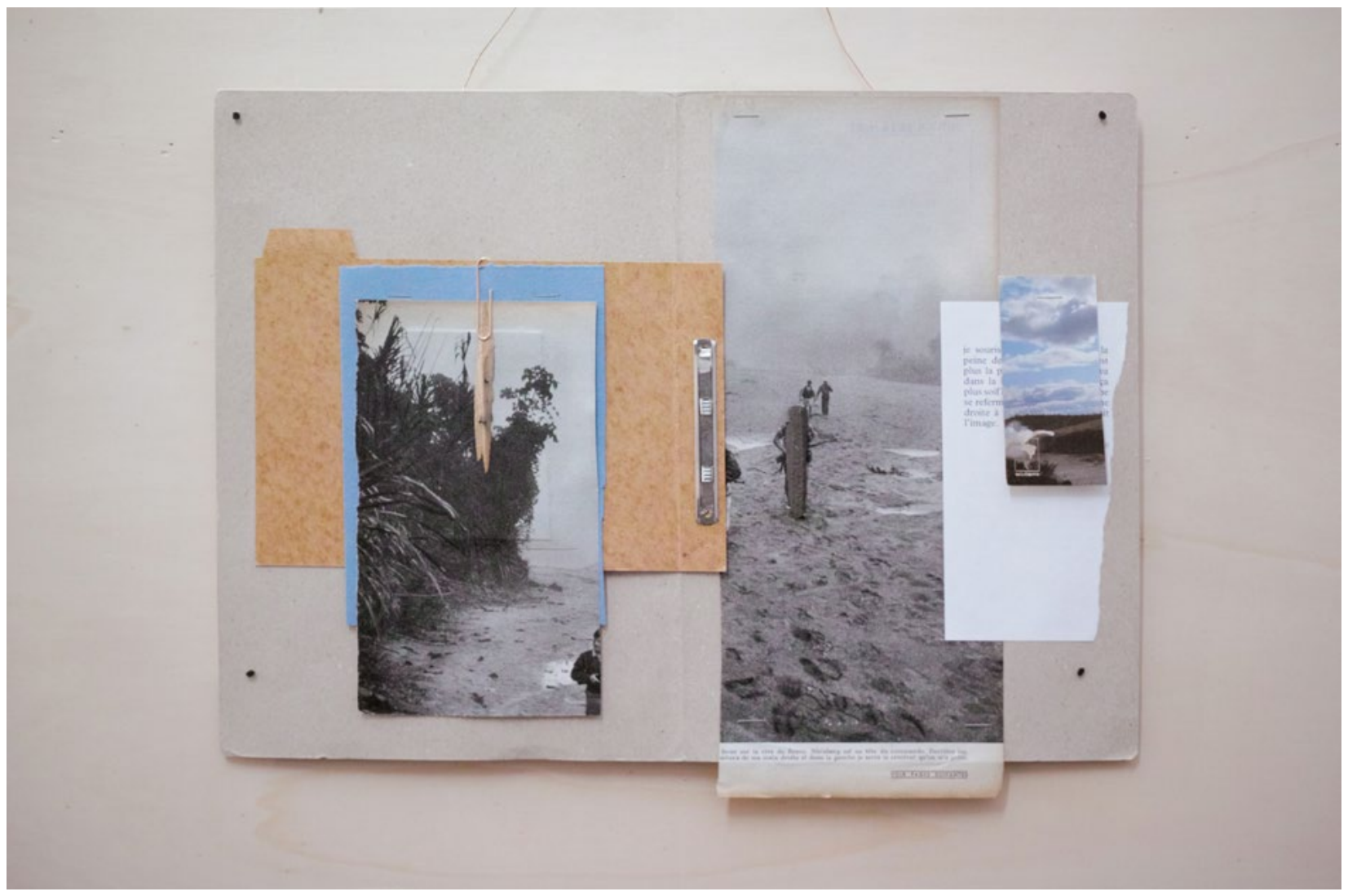

3.

Sem título | 2019

pasta de papelão, páginas de Paris Match

(1945), ardósia, madeira, clipe de papel

cobre, página do livro "A imagem"

de Samuel Beckett, cartão postal

$50 \times 45,5 \mathrm{~cm}$ 


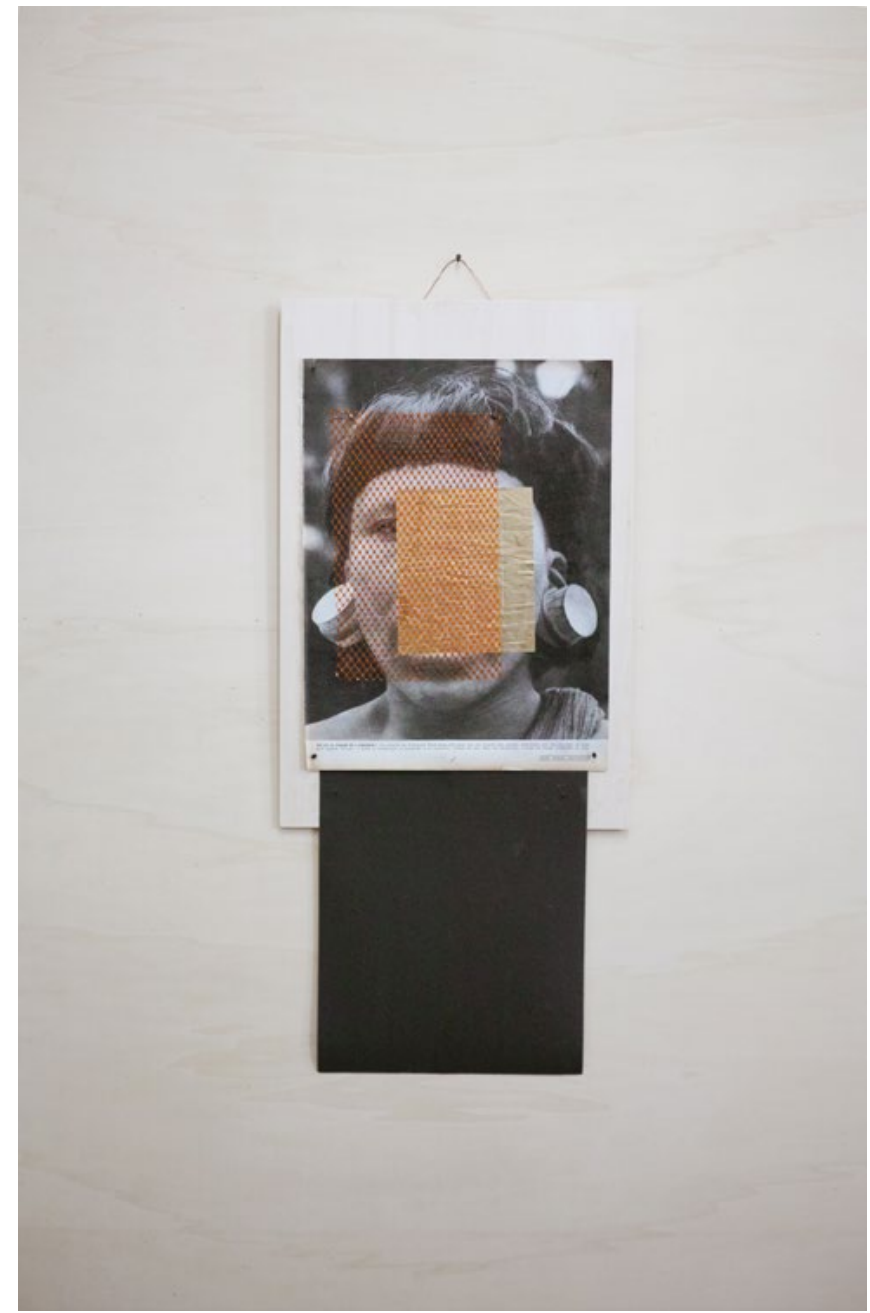

4.

Sem título | 2019

página de Paris Match (1945), rede, folha de ouro, cobre, lixa, pregos

$70 \times 30 \mathrm{~cm}$ 


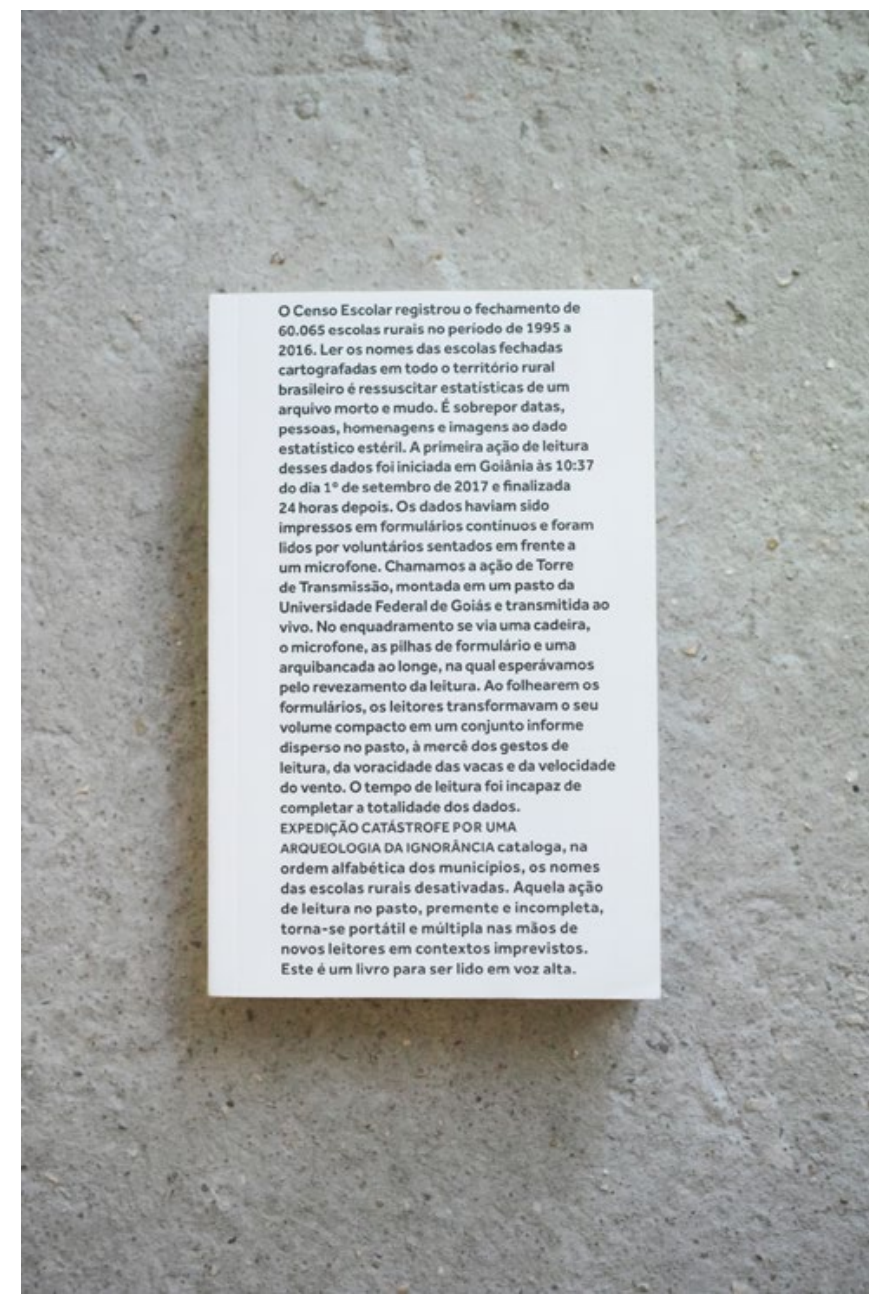

5.

Expedição catástrofe. Por uma arqueologia da ignorância, Rumos Itáu Cultural | 2017 performance e livro do artista com Alexandre Campos, Carolina Fonseca, Filipe Britto, Glayson Arcanjo, Pedro Britto, Laura Castro, Pablo Lobato, Renata Marquez

e YuriFirmeza

Lista de 60.065 escolas fechadas entre 1995 e 2016 na zona rural do Brasil 




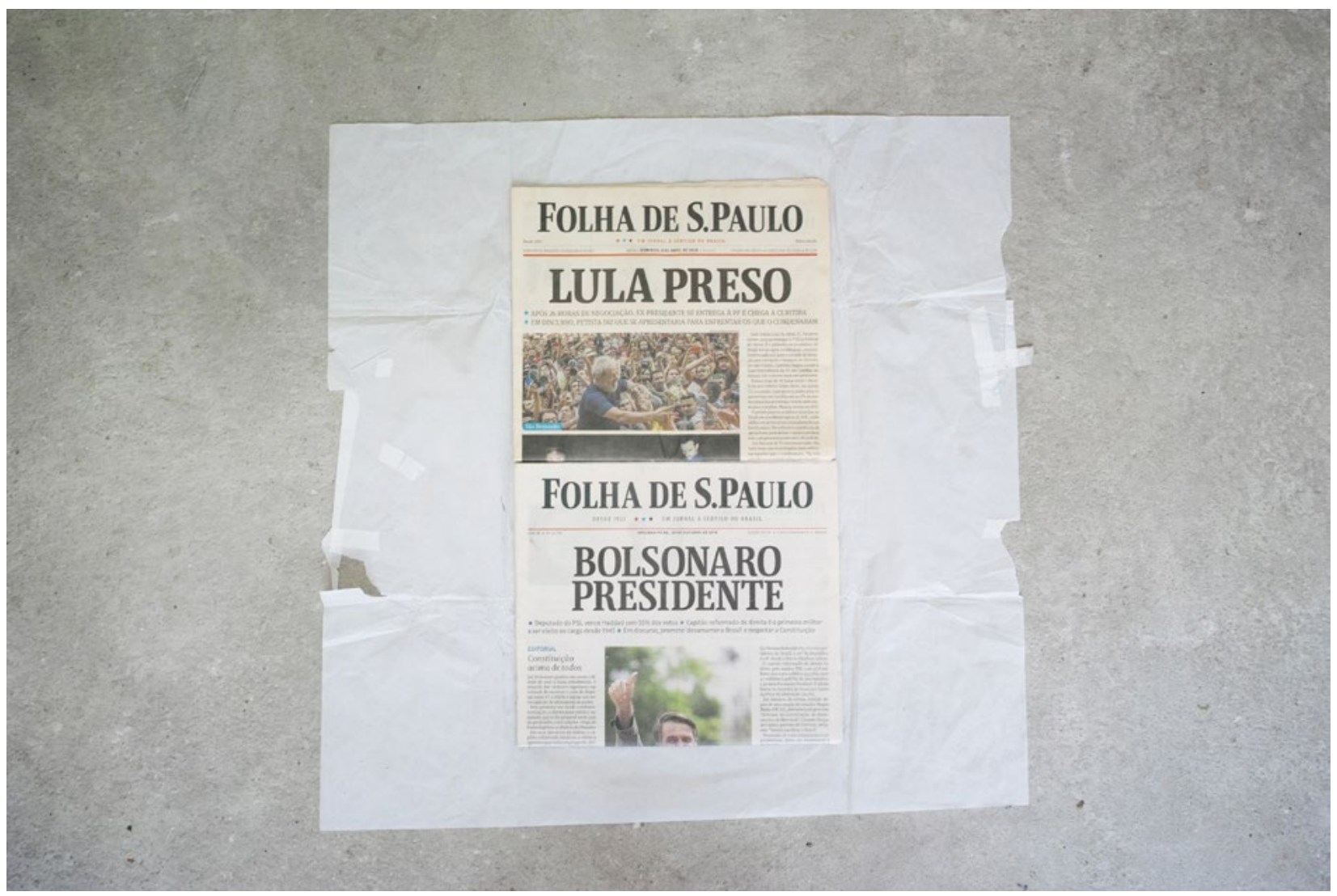

8.

Sem título | 2019

Jornais da Folha de São Paulo de 8 de abril de 2018 e 29 de outubro de 2018, papel de embrulho

$70 \times 70 \mathrm{~cm}$ 


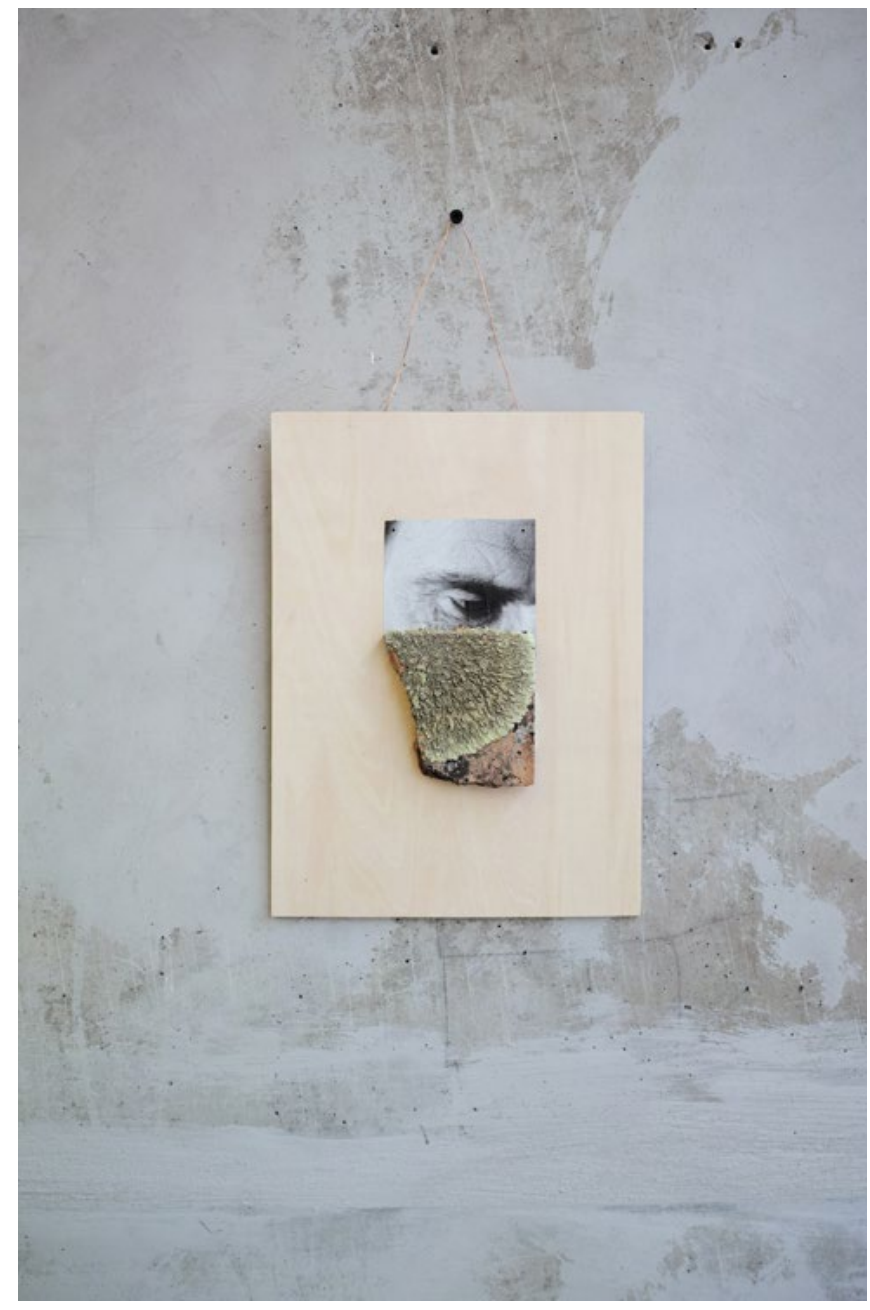

9.

Sem título | 2019

madeira, terracota, musgo, fotografia

$42 \times 22,5 \mathrm{~cm}$ 


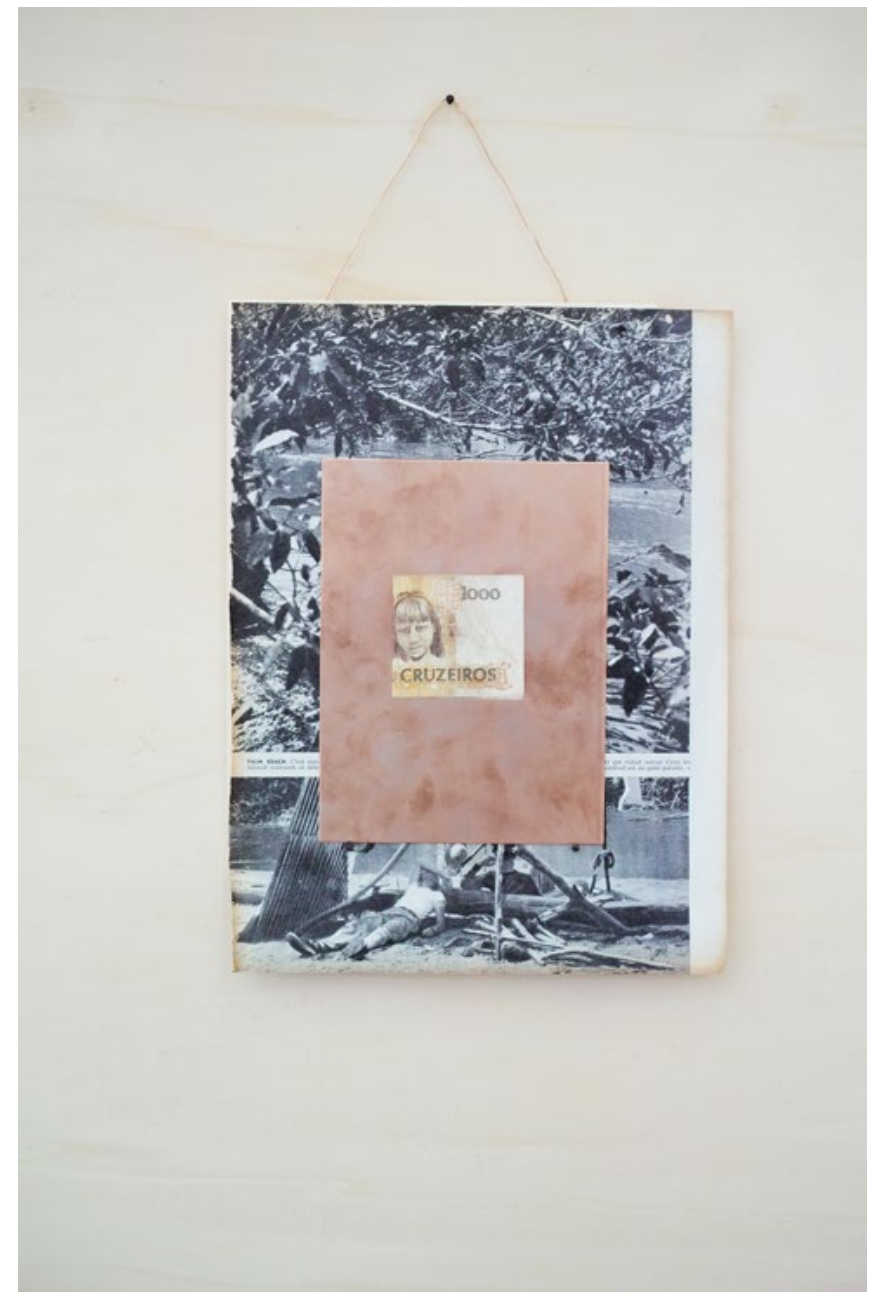

10.

Sem título | 2019

madeira, cobre, página de Paris Match

(1945), nota de mil cruzeiros

$46 \times 26,5 \mathrm{~cm}$ 


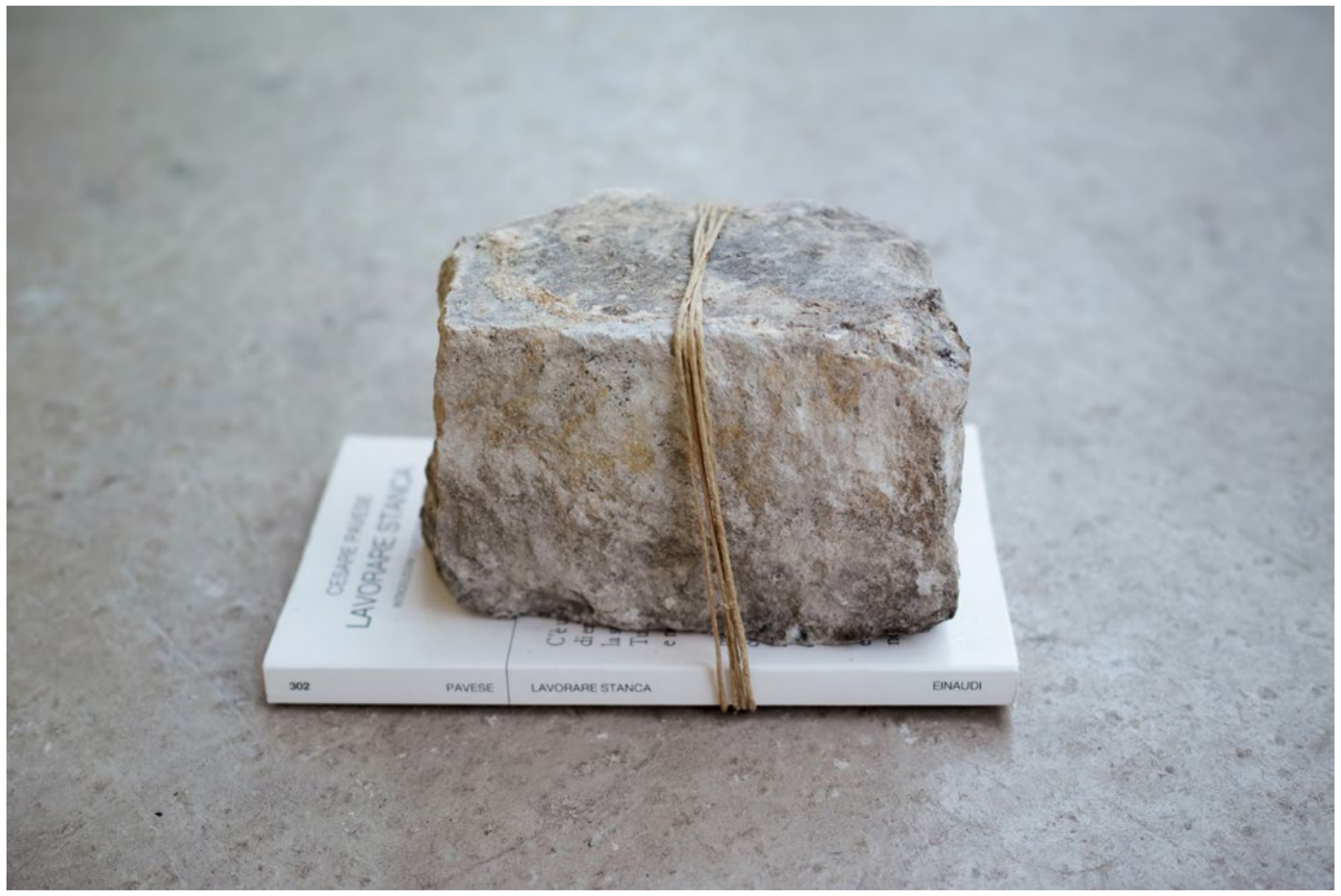

11.

Sem título | 2019

Calçada parisiense, cordão, edição italiana

de Lavorare stanca de Cesare Pavese

(1936)

$18 \times 10,5 \times 10 \mathrm{~cm}$ 


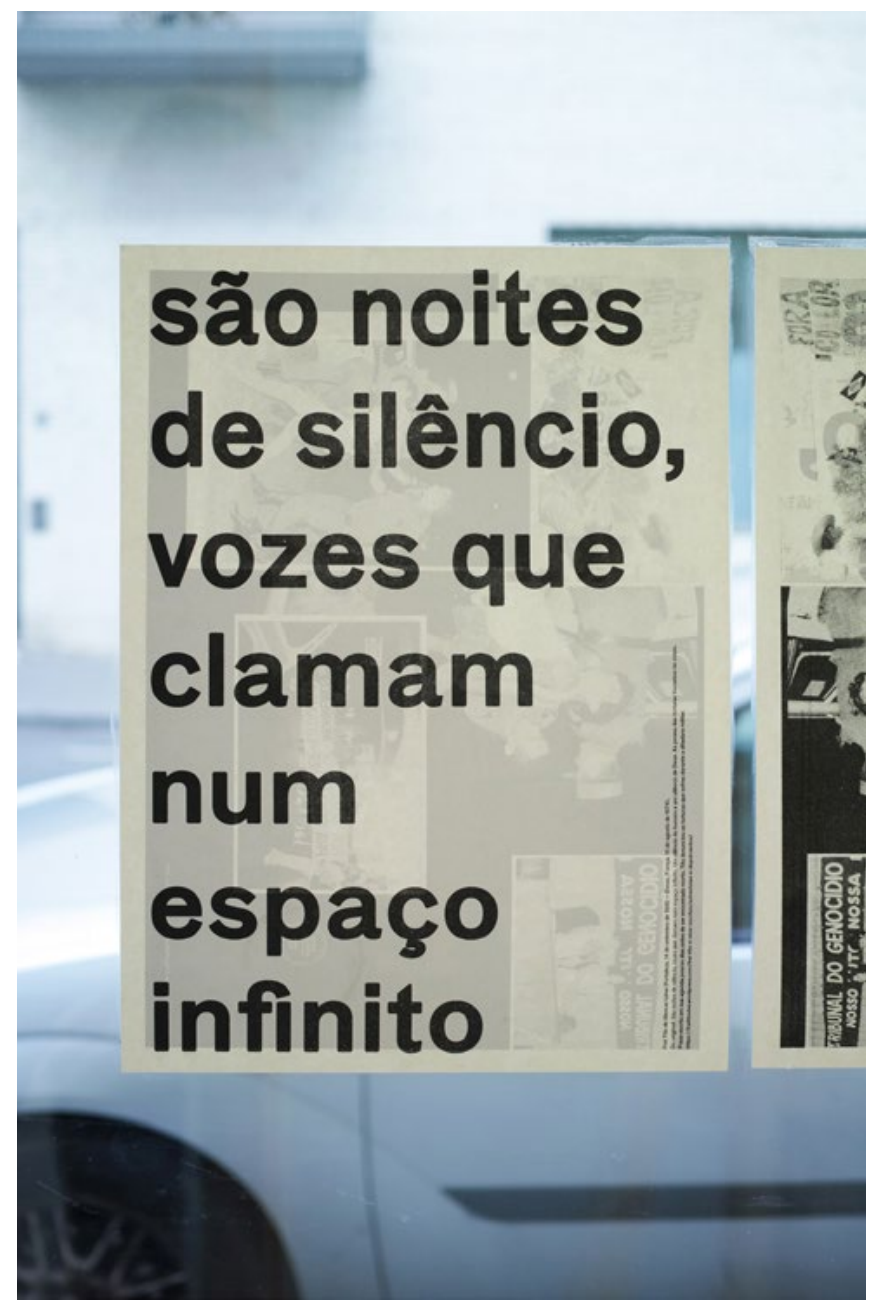

12.

Crítica Radical | 2019

com a colaboração de Lucas S. Icó

impressão em risografia

$42 \times 30 \mathrm{~cm}$ 


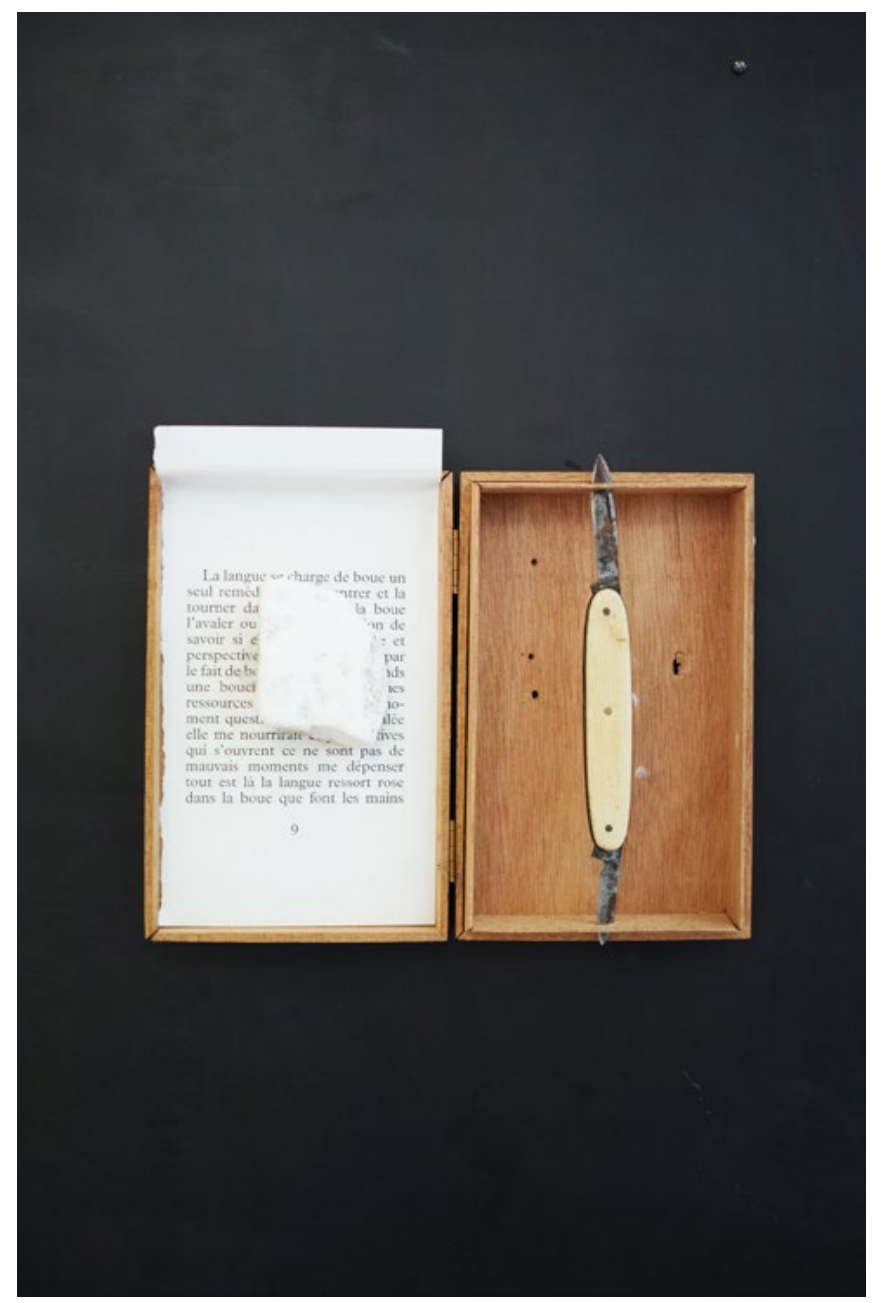

13.

Sem título | 2019

caixa de madeira, canivete, pedra, página

do livro "A imagem" de Samuel Beckett,

placa de pvc

$86 \times 61 \times 3 \mathrm{~cm}$ 


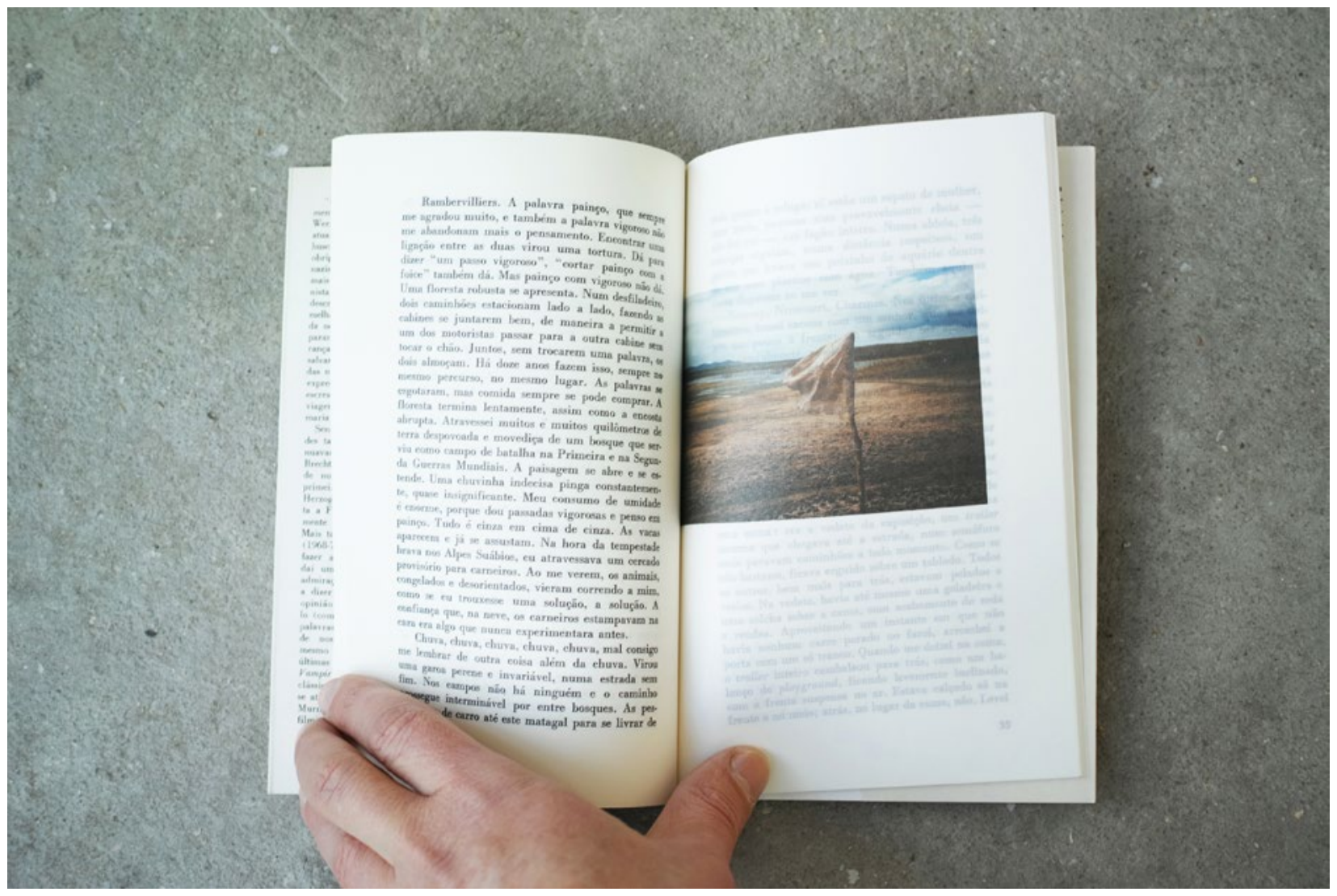

14.

Caminhando no gelo por Werner Herzog I

2016

livro de artista com a colaboração de Beat-

riz Lemos

$21 \times 14 \mathrm{~cm}$ 


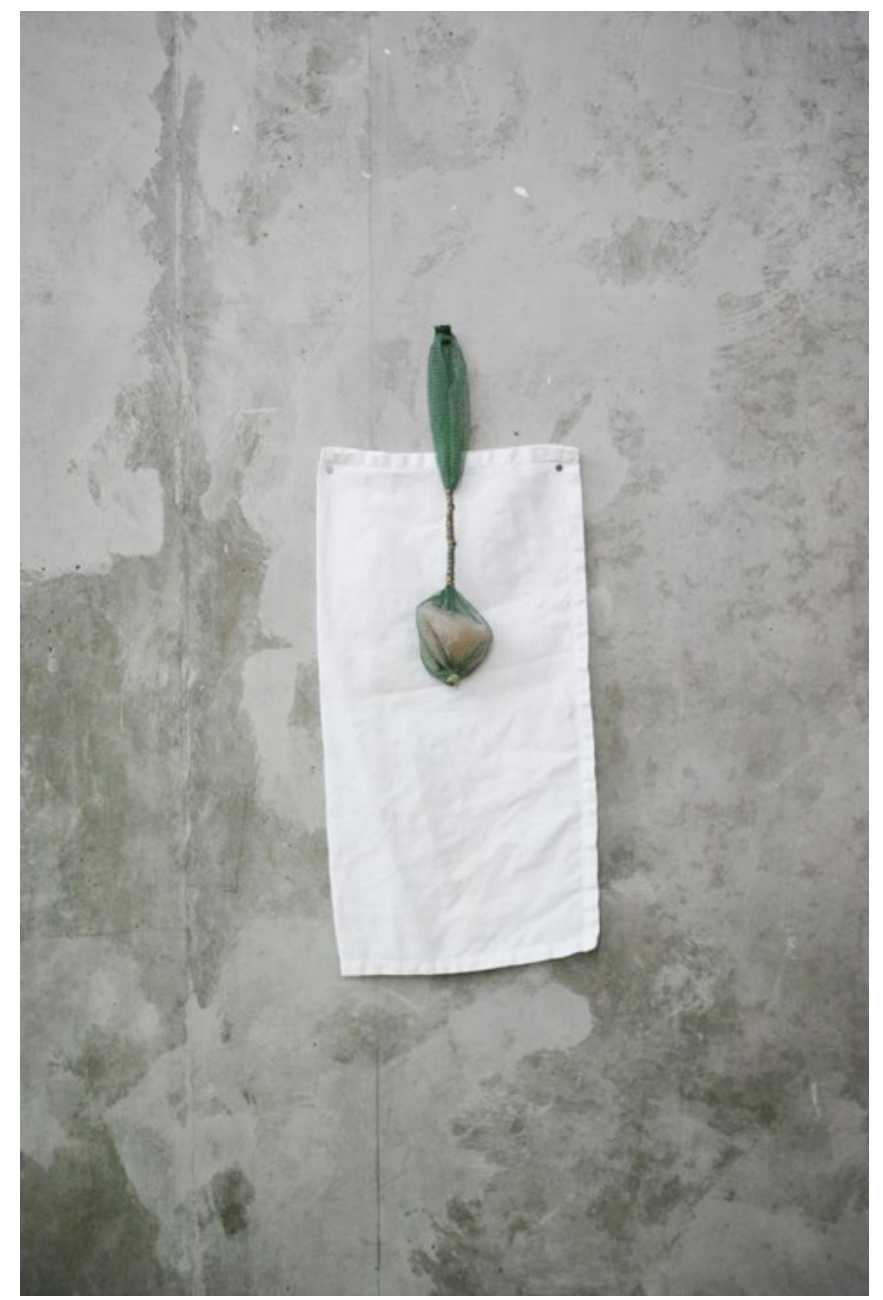

15.

Sem título | 2019

tecido, rede, cobre, quartzo rosa

$47 \times 19 \mathrm{~cm}$ 
Pacientemente e um pouco ao acaso, porém com uma curiosidade concentrada, ele tira da caixa o conteúdo que vai dispondo no chão. A imagem devota de uma Virgem azulada, um pedaço de pano endurecido que parece cartão costurado, uma carta manuscrita cujas primeiras linhas foram lidas sem as tentar entender e pequenas fotografias amareladas com cantos redondos e acizentados. Espalhados desta forma, montados como um quadro no atrito da areia, o conjunto funciona por afloramentos. Não que esses objetos venham da mesma caixinha de metal para dizer algo comum - o tempo, a costura da história -, mas esse ato de organizar e de montar que ĺcaro engendra, tem algo de edição. Documentário ou ficção, não interessa.

Sentada ao seu lado, vejo-o manusear os objetos no sótão da minha bisavó. Sem timidez, mas com a modéstia do estrangeiro em território íntimo, levanta tampas, puxa papéis de uma pilha de documentos, sopra poeira, pára em miniaturas de objetos infantis presas por uma corda áspera -, passa rapidamente para outros, faz perguntas, ouve. Não podemos dizer que está à procura de alguma coisa, mas essa ténue atenção que ele dá aos objetos, histórias que eles podem ou não contar, aos seus eventuais deslizes para outras histórias, reencontraria mais tarde ao caminhar nas ruas de Londres, trocando ideias sobre a exposição que estávamos preparando para a Galeria Salle Principale.

De há uns anos para cá, Ícaro Lira, um artista brasileiro de quem a primeira exposição individual em França foca a questão do deslocamento, controle e isolamento social. Uma história de fissuras e deslocamentos, a história da migração é mais do que uma história de origem - de onde se vem -, é uma história de circulação e de demarcação onde se vive, onde permanecemos, o que foi preciso para aí ficar. Uma demarcação em relação à terra nativa, é claro, mas também àquela sofrida, implícita ou explicitamente, na terra de recepção. O que é viver em algum lugar? Pertencemos ao lugar onde moramos? O que define a nossa pertença a determinado lugar? A que é que, mas também a quem somos estrangeiros? Dos territórios do nordeste brasileiro de onde ele vem e onde nunca pára de voltar, às ruas de São Paulo, Londres, Paris, Nápoles ou uma pequena vila andaluza, o artista vive em passagem. Não mais viajante do que exilado ou migrante, Ícaro Lira não celebra o nomadismo, mas está interessado nas transfigurações - políticas, económicas, sociais, mas também íntimas - que as circulações engendram. A partir das suas viagens, que são sobretudo encontros, traz objetos de volta: ripas de madeira, pedras, quadros, lixo, documentos administrativos, artigos de imprensa, mas também entrevistas em áudio e notas pessoais. Tantos traços com histórias singulares que, justapostos e em conjunto, formam uma malha de significado frágil aberta à interpretação.

Assim, pela acumulação díspares de detalhes, talvez inicialmente inócuo, algo provém do seu trabalho. Forma-se algo parecido com uma narrativa, ou algo que toma o lugar do rascunho do voluntário. Para silenciar o espaço, avançar nas histórias, deixar surgir as aproximações, como arquivista consciente, Ícaro Lira dedica-se, no entanto, à tarefa que lhe parece ser incumbida. Com as regras de classificação, separação e atribuição, prefere o acumular modesto e discreto de objetos heterogéneos e as linhas de fuga abertas por associações efémeras. Dizer mas preferir não. Procurar contar a história de trajetórias íntimas ou coletivas por agrupamentos frágeis e pouco ruidosos, para dar a ver linhas de significado irredutíveis às grandes narrativas. E com a voz monótona, prefere o arquivo 
íntimo, forma físsil e não homogénea por excelência. Assim, o deslocamento de um objeto sempre será possível e, com ele, uma escrita que incessantemente não se consegue concluir-se. Talvez seja o que Ícaro está tentando fazer aqui, um cesto de ficção: uma história que seria contada a partir de cacos e papéis enfiados às cegas no bolso da calça Jeans.

Os objetos e documentos coletados e montados por Lira constituem um agenciamento plástico a par de uma dicção poética. Assemelha-se a uma prosa interior na qual o olhar e o pensamento vêm fundir-se aos gestos repetidos de deslocamento, de justaposição, de separação, de recuperação e associação. Os objetos funcionam igualmente como significantes como sinais. Para lá do valor documental que uma fotografia tirada da revista Paris Match ou que uma nota de mil cruzeiros possa ter, parece-me que existem dois modos de se relacionar com o real. O primeiro baseado numa lógica de índice, o documento, como um vestígio, referindo-se a um regime específico de conhecimento e de representação, é um veículo de acesso ao passado. A essas histórias prolongadas no tempo e aos silêncios que, para se tornarem de membranas tão finas, devem a existência ao palimpsesto de vozes e de memórias. Mas, mesmo assim, seria imediatamente devedor na sua função de prova pelas manipulações e deslocamentos que o artista lhe fez passar. O outro, mais precário, revelaria um pensamento: um pensamento como aquilo que resiste precisamente ao inteligível. Neste sentido, com detalhes tais como uma romã seca ou um pedaço de ardósia, Ícaro trabalha mais com conotações do que com certezas, conseguindo, na sua própria insignificância, atingir algo do real. Seria errado conceber esses documentos e objetos como único meio de acesso aos fatos, buscar nos seus pormenores uma linha de sentido que lhe concedesse toda a importância e justificasse a sua presença no dispositivo aqui implantado. Em vez disso, levam-nos a pensar em como aceder os fatos que conseguem contar. Duas edições da imprensa nacional brasileira - A Folha de São Paulo - uma de 8 de abril de 2018, outra de 29 de outubro de 2018, estão dispostas lado a lado, no chão, no papel que serviu para proteger e transportá-las. Uma anuncia a prisão de Lula, outra a nomeação de Bolsonaro para presidente do Brasil. Ícaro transportou consigo esses dois números na mala, por um ano, sem saber o que lhes haveria de fazer. Nem o fazer com aquilo que eles enunciam. Leveza, não tenho certeza - preso / peso (prisioneiro / peso). A sua materialidade resiste ao discurso.

As montagens de Ícaro iludem qualquer forma de integração num discurso excedente, são avessas à linearidade e demonstração. Preferindo a possibilidade de investimento íntimo à síntese de um discurso totalizador. O paradigma de indexação é, portanto, bloqueado. Depositados aqui e ali, objetos como um pedaço da rocha obsidiana, figurinhas de Chiquilin ou um livro, acompanham as obras - elas próprias feitas de outros objetos -, enfatizando a sua dimensão material e irredutível. A obra torna-se, assim, o espaço expositivo de uma coleção pessoal, onde se pode ler trechos de histórias, que giram constantemente em torno dos vestígios que Ícaro vai recolhendo. Nesse conjunto os objetos nunca funcionam em bruto, mas engajados numa lógica de montagem e de exibição. Portanto, é menos a restituição de uma história que se desenrola diante de nossos olhos do que um relacionamento íntimo com ela. 
Por essa abordagem que não pretende de todo fechar-se, mas oferecer-se, como escuta, à pluralidade de histórias e vozes, à sua vulnerabilidade, Ícaro Lira dá conta de uma profunda empatia pelas experiências vividas. A exposição na galeria Salle Principale aparece como um nó. Um nó temporário de vozes, encontros e histórias, de territórios atravessados, habitados e carregados em cada um, de temporalidades distintas constantemente reconduzidas por colagens renovadas. Neste sentido, não atua no modo da instituição, mas mais no ato de quebrar e abrir. A enunciação é plural e especular. Faz-se ouvir de repente, nas sequências e articulações da montagem, no eco dos encontros que o viram nascer e que faz suscitar.

\section{Elena Lespes Muñoz}

Paris (1988). Vive e trabalha em Paris. Historiadora de arte (Universidade de Paris I e Universidade de São Paulo). Coordenou projetos em arte contemporânea na Fundação Kadist. Trabalhou na associação Artesur (dedicada à arte contemporânea na América Latina) e na Galeria Aline Vidal, além de curadora de exposições (Le bruit des choses qui tombent, FRAC-PACA, 2017; Video SUR, Palais de Tokyo, 2018). Atualmente, é gestora de comunicação e mediação da CAC Brétigny. 
dossiê visual - ícaro lira revista poiésis 35

janeiro 2020 